\title{
Consumer Preferences for Types of Cost Containment in Prescription Drug Programs
}

\begin{abstract}
OBJECTIVE: To estimate (1) the relative importance of three major attributes of prescription drug benefit plans-level of copayment, pharmacy access, and access to products-that health plans use to control prescription drug expenditures and (2) the trade-offs that consumers make among these attributes.
\end{abstract}

DESIGN: Self-administered survey and conjoint analysis of consumer preference data.

PARTICIPANTS: A convenience sample of 130 consumers in Richmond, Va.

MAIN OUTCOME MEASURES: Consumer preference ratings for 11 hypothetical drug benefit plans; relative importance consumers attributed to level of copayment, pharmacy access, and access to products in selecting drug benefit plans; trade-offs consumers made among these attributes.

RESULTS: Product choice was the most important attribute in selecting a drug benefit plan. The importance rating was $42.1 \%$. Consumers indicated strong preferences for open formularies. Level of copay received an importance rating of $31.9 \%$. Higher copays were associated with lower consumer preference. Choice of pharmacy had an importance value of $26.0 \%$. Consumers preferred plans that allowed either free choice of pharmacy or that included their current pharmacy. A market segmentation analysis yielded similar results.

CONCLUSIONS: Conjoint analysis provides useful consumer preference and trade-off information that health plans could use to minimize consumer dissatisfaction with drug benefit plans.

KEYWORDS: Conjoint analysis, Cost control, Cost sharing, Copayment, Formulary, Network, Consumer preference, Trade off analysis.

J Man Care Pharm 2002;8(3):192-98 by David Holdford, R.Ph., M.S., Ph.D., and

Norman V. Carroll, R.Ph., Ph.D.

T he escalating cost of outpatient prescription drugs has caused concern for employers and other payers for pharmaceutical products and services. The Health Care Financing Administration (now Center for Medicare and Medicaid Studies) reported that the rate of growth in prescription expenditures in the United States has increased each year since 1994, to an average annual increase of $15.4 \%$ in $1998 .{ }^{1}$ By comparison, the annual growth in total health care expenditures in 1998 was only 5.6\%. ${ }^{1}$ As a result, prescription drugs have become a primary target for cost containment efforts.

Managed care organizations (MCOs) have employed a variety of types of efforts to control the costs of prescription drugs. These efforts can be categorized into three general groups: increased patient cost sharing, restrictions on choice of products, and restrictions on choice of pharmacy. These efforts are usually implemented through use of copayments, formulary policies that encourage substitution of generic or therapeutically equivalent drugs for brand-name prescription drugs, and use of closed pharmacy networks.

Despite the widespread and increasing use of such techniques, MCOs may implement cost containment strategies without a clear understanding of their consequences on consumer satisfaction. For instance, little is known about how consumers perceive and respond to restrictions on access to drugs or pharmacies. This may lead managers of drug benefit plans to design programs based upon preconceived and potentially incorrect assumptions about consumer preferences. The outcome of this situation may be dissatisfied consumers who switch to health care plans that better meet their needs and wants.

This study was designed to address the question, "What attributes are important to consumers when designing pharmacy benefit plans?" Specifically, the objectives of this study were to: estimate the relative importance of three major attributes of prescription drug benefit plans, estimate the trade-offs that consumers make in selecting among different pharmacy benefit attributes, and identify segments of consumers based on their preferences for drug benefit plan attributes.

\section{Methods}

Satisfaction surveys are the most common technique used by managed care researchers to understand consumer choices 
for various elements of health care plans (e.g., accessibility, price). ${ }^{2}$ A complaint about consumer satisfaction surveys in managed care is that they are typically conducted to promote the plan to new enrollees rather than to understand consumer perceptions of plan services. ${ }^{2}$ Another problem with satisfaction surveys, as with other uses of rating scales and ranking procedures, is that they ask respondents to evaluate individual attributes of plans one at a time, in isolation from other plan attributes. This approach fails to frame questions in a manner that will elicit the trade-offs made in actual consumer decisions. For example, consumers do not evaluate the quality of a health benefit plan independent of cost and accessibility. Preferences for plan quality are affected by the size of the premiums and breadth of the provider network.

To avoid these problems, this study used conjoint analysis to elicit consumer preferences for different attributes of drug benefit programs. Conjoint analysis (CA), a commonly used marketing research method, ${ }^{3}$ is designed specifically to mimic the decision process that consumers use in choosing products and services. Consumers are asked to assess all elements of a product or service simultaneously instead of independently, as seen with other techniques such as satisfaction surveys. CA has been used to study consumer preferences for drug therapies ${ }^{4-7}$ pharmaceutical services, ${ }^{8-10}$ health outcomes, ${ }^{11-18}$ and health insurance, ${ }^{3,19}$

With CA, respondents are asked to evaluate a hypothetical product profile (i.e., a description of the product or service being evaluated) and give an overall preference for that product profile based upon the individual attributes used to describe it. The process is repeated for other profiles that alter the levels of the product's attributes. The respondent's profile preferences are then analyzed to determine the relative importance of each attribute in determining the respondent's overall preference for the product or service. In this study, consumers' preferences for different drug benefit plans were used to determine the relative importance placed on patient cost sharing, pharmacy restrictions, and product choice limitations.

Our study employed a part-worth function model. This model assumes that a consumer's overall preference for a multi-attribute product is the sum of the importance the consumer places on each of the product's attributes. This model is flexible in its assumptions, widely used, and widely accepted by academics and industry researchers in marketing. ${ }^{20}$

Each drug benefit plan in our study was described by three attributes - cost-sharing, access to pharmacy, and formulary (drug list) restrictiveness. The attributes were chosen after a thorough review of the literature on pharmacy patronage, patient satisfaction, and prescription drug benefit plans. Each attribute represents a different method of cost containment and together they allow consumers to trade off cost, service, and access.

Three levels of each attribute were specified (see Table 1). The levels were selected to capture the full range of values for each attribute that consumers might see in the market and to vary sufficiently so that respondents can detect differences.

\begin{tabular}{ll}
\hline TABLE 1 & $\begin{array}{l}\text { Attributes and Levels Used } \\
\text { in the Analysis }\end{array}$ \\
\hline Attribute & Level \\
\hline Access to pharmacy & $\begin{array}{l}\text { 1. Can use any pharmacy } \\
\text { 2. Insurance plan has a restricted network but } \\
\text { patient's usual pharmacy is included } \\
\text { 3. Insurance plan has a restricted network and } \\
\text { patient must switch to a new pharmacy }\end{array}$ \\
\hline Patient cost-sharing & $\begin{array}{l}\text { 1. No copay } \\
\text { 2. } \$ 8 \text { copay per prescription }\end{array}$ \\
$\begin{array}{l}\text { 3. } \$ 15 \text { copay per prescription } \\
\text { Formulary }\end{array}$ & $\begin{array}{l}\text { 1. Open formulary - the plan covers any } \\
\text { medicine the physician prescribes }\end{array}$ \\
$\begin{array}{l}\text { 2. Mandatory generics - the plan covers only } \\
\text { generic products if they are available }\end{array}$ \\
$\begin{array}{l}\text { 3. Closed formulary - the plan has a limited and } \\
\text { restricted list of drugs that it will cover. Any } \\
\text { drugs not on the list must be switched to a } \\
\text { similar drug on the list or the patient must pay } \\
\text { out of pocket }\end{array}$
\end{tabular}

We used a fractional factorial design to reduce the number of different drug benefit plans viewed by respondents. Eleven plans were presented to consumers. Nine were used to develop importance estimates. The other two were used as a holdout sample to assess the accuracy of the estimates.

Plans were presented as written descriptions of benefits and restrictions for prescription copayment, choice of pharmacy, and limitations of formulary. A full profile approach to data collection was used in this research. Profiles were pretested on students and university employees to identify unclear or ambiguous choices. A copy of a profile is provided in Figure 1 (next page). Consumers were asked to rate each plan on a 10-point scale. A score of "1" indicated that they would be unlikely to choose that benefit plan and a score of "10" indicated they would be likely to choose that plan. Intermediate points in the scale were not defined.

The drug benefit plans were presented to consumers as part of self-administered written questionnaires. Responses were collected from a convenience sample of consumers in the Richmond, Virginia, area.

\section{Estimation of Utilities and Importance Values}

The PC-SAS program TRANSREG was used to estimate partworth utility values ${ }^{21}$ for each consumer. The metric conjoint option was used. The TRANSREG program uses OLS regression analysis to estimate part-worths. The output of the program was a part-worth utility score for each level of each attribute for each respondent.

\section{Market Segmentation Analysis}

The CA results also were used to conduct a segmentation analysis. This analysis assigned respondents to segments based on the 


\section{FIGURE 1 Sample Conjoint Profile}

Please look over the prescription drug plan below and then circle the number on the scale at the bottom of the page to indicate how likely you would be to choose the plan.

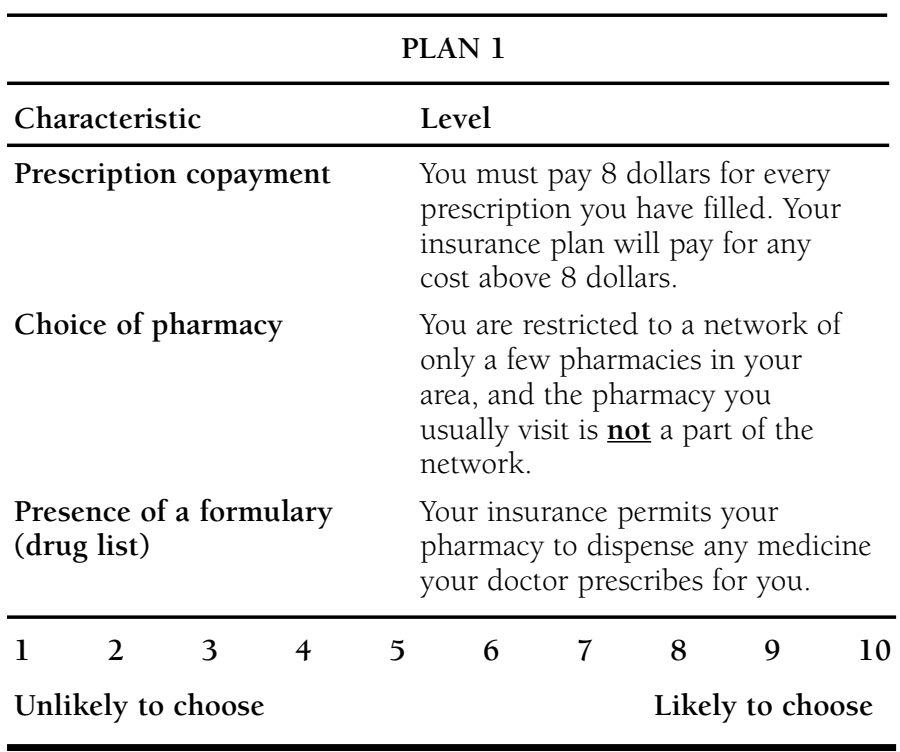

TABLE $2 \longdiv { \text { Demographic Description of Sample } }$

\begin{tabular}{|c|c|c|c|}
\hline Sex & & Frequency & Percent \\
\hline & Female & 86 & 66.7 \\
\hline & Male & 43 & 33.3 \\
\hline \multicolumn{4}{|l|}{ Income } \\
\hline & Less than $\$ 10,000$ & 3 & 2.8 \\
\hline & $\$ 10,000$ to $\$ 29,999$ & 25 & 23.6 \\
\hline & $\$ 30,000$ to $\$ 49,999$ & 23 & 21.7 \\
\hline & $\$ 50,000$ to $\$ 74,999$ & 32 & 30.2 \\
\hline & $\$ 75,000$ or more & 23 & 21.7 \\
\hline \multirow{6}{*}{$\begin{array}{l}\text { Prescription } \\
\text { payer }\end{array}$} & & & \\
\hline & Government & 3 & 2.4 \\
\hline & Private insurance & 28 & 22.4 \\
\hline & $\mathrm{HMO}$ & 71 & 56.8 \\
\hline & Self & 16 & 12.8 \\
\hline & Other & 7 & 5.6 \\
\hline \multicolumn{4}{|l|}{ Age (in years) } \\
\hline & 18 to 24 & 10 & 7.8 \\
\hline & 25 to 44 & 72 & 56.2 \\
\hline & 45 to 64 & 39 & 30.5 \\
\hline & 65 or over & 7 & 5.5 \\
\hline \multicolumn{4}{|l|}{ Marital status } \\
\hline & Never married & 32 & 24.8 \\
\hline & Married & 81 & 62.7 \\
\hline & Divorced & 9 & 7.0 \\
\hline & Separated & 2 & 1.6 \\
\hline & Widowed & 5 & 3.9 \\
\hline \multirow{4}{*}{$\begin{array}{l}\text { Highest level } \\
\text { of education }\end{array}$} & Postgraduate & 37 & 28.7 \\
\hline & College graduate & 40 & 31.0 \\
\hline & High school & 49 & 38.0 \\
\hline & Less than high school & 3 & 2.3 \\
\hline
\end{tabular}

strength of their preferences for the attributes. Consumers were assigned to either copayment, formulary, or pharmacist choice segments if their importance values for one of these attributes was at least $40 \%$ and if it was at least 10 percentage points greater than the importance they placed on the other attributes. Those individuals who did not fall into any of these single preference categories were considered to have mixed preferences.

Respondents with mixed preferences were further assessed to determine which two attributes they most preferred. These respondents were assigned to a segment based on cumulative importance values of at least $70 \%$ for at least two attributes when the importance values for attributes were within 10 percentage points of each other.

\section{Assessment of the Conjoint Model}

The internal reliability of responses was assessed by measuring the CA model's goodness of fit. The validity of the data was assessed using a method suggested by Acito and Jain..$^{22}$ The method tests whether the predicted values calculated from the CA estimates are more accurate predictors of the actual values of the holdout profile than are random values.

\section{Results}

Data were collected from 130 consumers. A demographic description of respondents is shown in Table 2. Responses for three consumers could not be used in calculating utilities due to incomplete responses on the survey. The sample was predominantly female and married. Most were college graduates with family incomes of greater than $\$ 50,000$ per year. Most received prescription benefits through an HMO. On average, respondents purchased 6.0 (+/- 7.1 $\mathrm{SD})$ prescriptions per year for themselves or other family members. The range of purchases was from 0 to 40 prescriptions per year.

Part-worth utility values (UVs) are shown in Table 3 (next page). The importance values estimated from the CA model indicated that formulary status was the most important attribute ( $42.1 \%$ out of a possible $100 \%$ ) in determining a consumer's preference for a prescription benefit plan. Consumers strongly preferred open formularies. As formulary restrictiveness increased, preferences decreased. The change in preference was more than twice as great for a change from a mandatory generic policy to a restricted drug list than for a change from no formulary to a mandatory generic policy.

The next most important attribute was the amount of the copayment (31.9\%). Increasing the copayment from $\$ 8$ to $\$ 15$ had about three times more impact on consumer preference than increasing it from no copayment to an $\$ 8$ copayment.

Restricting access to pharmacies had an importance value of $26.0 \%$. Consumers had approximately equal preferences for an open network and a closed network that included their usual pharmacy. That is, they saw no disadvantage to a restricted network if it included the pharmacy at which they usually purchased 
prescriptions. Preferences were only affected if the restricted network did not include their usual pharmacies.

\section{Market Segmentation Analysis}

The results of the market segmentation analysis are shown in Figure 2. Forty-four percent of respondents based their decisions primarily on formulary choice, $23 \%$ based their decisions primarily on copayment, and the smallest number $(10 \%)$ on pharmacy access. Of the 30 respondents who expressed mixed preferences, $21(70 \%)$ indicated that formulary choice was a major determinant of their choice.

\section{Correlation Analysis}

No significant relationships between the importance of pharmacy choice or formulary status were indicated for either the demographic variables or annual prescription purchases. Results did indicate that level of copay was less important to higher income groups ( $\mathrm{F}$ with $4,98 \mathrm{df}=2.96, \mathrm{p}=0.0234$ ) and married respondents ( $\mathrm{F}$ with $1,124 \mathrm{df}=4.3, \mathrm{p}=0.040$ ). While there were significant differences among age groups in the importance of copay ( $F$ with $5,119 \mathrm{df}=3.64, \mathrm{p}=0.004$ ), there was no clear pattern.

\section{Assessment of the Conjoint Model}

The goodness of fit of the conjoint model $\left(\mathrm{R}^{2}\right)$ was 0.88 , indicating a good fit of the data to the model. The mean (SD) absolute value of the differences between predicted and actual values for the two holdout profiles were 3.0 (1.9) and 2.2 (1.6). By comparison, the mean absolute value of the differences between the actual values and randomly selected values was 3.6 (2.6). A Z-test indicated that the values predicted from the conjoint results were significantly $(p<0.05)$ more accurate than random values.

\section{Discussion}

The purpose of this study was to determine the relative importance of prescription drug benefit attributes in consumer selection of drug benefit plans. The results indicated that, given the levels of attributes specified in this study, preferences for drug benefit plans were most influenced by formulary restrictions for this sample of respondents. Respondents strongly opposed closed formularies and, to a much lesser extent, mandatory generic policies. This is particularly noteworthy in light of the increasing use of formulary restrictions on branded products. Use of restricted formularies has increased from 23\% of HMOs in 1992 to 49\% in 1999. 23,24 Use of closed formularies in employer-sponsored plans has remained relatively stable since 1995, but use of incentive formularies has grown from "a few plans" in 1996 to 25\% of responding plans in 1999.25,26

As expected, consumers most preferred to have no copay and least preferred the $\$ 15$ (highest) copay. They also indicated that the change from an $\$ 8$ copay to a $\$ 15$ copay was three times more important than a change from no copay to an $\$ 8$ copay. This may suggest that consumers have become accustomed to paying small copays, but that they are resistant to paying larger copays.

\begin{tabular}{|c|c|c|c|c|}
\hline TABLE 3 & $\begin{array}{l}\text { Utility } \\
\text { Estime }\end{array}$ & $\begin{array}{l}\text { hts } \\
\text { r Ph }\end{array}$ & $\begin{array}{l}\text { Importa } \\
\text { macy Attr }\end{array}$ & $\begin{array}{l}\text { e } \\
\text { utes }\end{array}$ \\
\hline & Mean & SD & Confidence & Interval \\
\hline Copay & & & & \\
\hline No copay & 0.380 & 1.022 & 0.291 & 0.425 \\
\hline$\$ 8.00$ & 0.162 & 1.193 & 0.058 & 0.215 \\
\hline$\$ 15.00$ & -0.541 & 1.094 & -0.636 & -0.493 \\
\hline Importance & 0.319 & & & \\
\hline Pharmacy choice & & & & \\
\hline Any pharmacy & 0.184 & 0.888 & 0.107 & 0.223 \\
\hline Same pharmacy & 0.341 & 0.784 & 0.273 & 0.376 \\
\hline Different pharmacy & -0.525 & 1.120 & -0.623 & -0.476 \\
\hline Importance & 0.260 & & & \\
\hline Formulary & & & & \\
\hline None & 0.638 & 1.699 & 0.490 & 0.713 \\
\hline Mandatory generics & 0.226 & 1.288 & 0.114 & 0.284 \\
\hline Restricted drug list & -0.864 & 1.137 & -0.963 & -0.814 \\
\hline Importance & 0.421 & & & \\
\hline
\end{tabular}
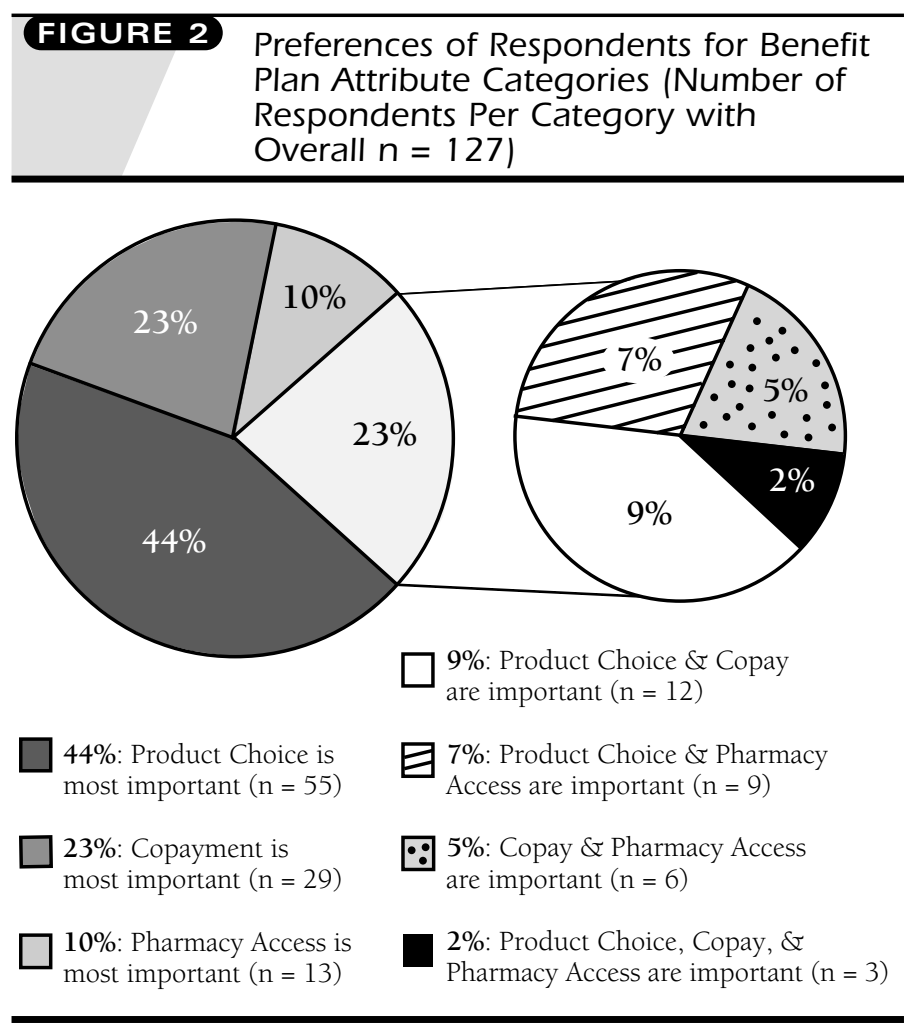

Access to their usual pharmacy was much less important to consumers than formulary restrictions and somewhat less important than copay amount. To explain the relative importance of the attributes in another way, a change in formulary status from open to closed (restricted drug list) had nearly as much effect on consumer preference as both the implementation of a closed network that did not include the consumer's usual pharmacy and the implementation of a $\$ 15$ copayment.

The market segmentation analysis provided similar results as to 
the relative importance of attributes. Most consumers made their choice of plan based primarily on formulary status, fewer based their choice primarily on copay level, and the fewest based their choice on pharmacy access. Figure 2 shows that over $75 \%$ of respondents made their plan choices based on a single plan attribute while the remaining respondents made their choice based upon multiple attributes.

The segmentation analysis also provides insight into individual preferences for plan attributes. Although formulary status and copay are clearly preferred by most respondents when choosing a plan, 21 respondents placed great emphasis on pharmacy access in choosing plans (i.e., 13 with most important and 8 with mixed preference for one other attribute). This consumer segment might be likely to respond negatively to restricted pharmacy networks.

Our study did not specifically examine consumer preferences for three-tier copay plans. To some extent, this is a limitation because of the wide use of three-tier copay design in drug benefit plans today. Recent surveys indicate that three-tier copays covered $40 \%$ of $\mathrm{HMO}$ enrollees ${ }^{27,28}$ and $50 \%$ of enrollees of health plans sponsored by large employers in fall 2000. ${ }^{28}$ This is up from only $5 \%$ of enrollees in three-tier plans in the spring of 1998 and is expected to continue to grow..$^{27,28} \mathrm{~A}$ recent report also indicates that insurers and PBMs are beginning to offer plans with more than three tiers. ${ }^{29}$ Consequently, information on consumer preferences for these features would be important information for those designing drug benefit programs.

While our study did not specifically address multiple-tier copay programs, the results may shed some light on consumer preference for them. The results indicated that consumers were willing to pay significantly higher copays to avoid closed formularies. This is basically what tier copay plans allow them to do-pay higher copayments for drugs otherwise not covered (100\% costshare). As such, our results indicate that consumers would prefer tier copay programs to closed formularies.

In addition, the results suggest the ranges of copay differences within which consumers would prefer tier-copay benefit plans. Specifically, the utility value associated with the change from a mandatory generic policy to a closed formulary was 1.09. This is substantially larger than the utility value of a change in copay from $\$ 8$ to $\$ 15(0.703)$ and a little larger than the utility value of a change from $\$ 0$ to $\$ 15(0.921)$. This can be interpreted to indicate that consumers would almost surely be willing to pay $\$ 7$ more per prescription, and probably would be willing to pay $\$ 15$ more, to have their choice of drug products as opposed to being subject to a closed formulary. This suggests that copay differences between the brand-name drug on the formulary and the brandname drug not on formulary tiers need to be substantially higher than $\$ 15$ to induce consumers to switch from nonformulary to formulary products.

\section{Limitations}

The results of the study are subject to several limitations. First, the results are based on a small, convenience sample from one area of the country. It is not known whether similar results would be obtained from a larger, more nationally representative sample. The respondents in our sample do differ slightly from national averages on prescription use. Sample respondents reported mean prescription purchases of about six prescriptions per year. These purchases included prescriptions the respondent purchased for his or her own use as well as ones purchased for family members. National statistics from HMOs indicate higher usage rates of about eight prescriptions per member per year for younger consumers and 22.5 prescriptions per member per year for Medicare recipients. ${ }^{23}$

Second, the results apply only to the particular levels of attributes specified in the study. For example, the results can only indicate preferences for the copayment levels specified. No conclusions can be made for copayments of $\$ 25, \$ 35$, or any other levels that were not explicitly assessed. Third, the results do not allow for linear extrapolation. The utility weights indicate that a change in copay from $\$ 0$ to $\$ 8$ has less effect on consumer preference than a change from $\$ 8$ to $\$ 15$. If the utilities were linear these two changes should have about equal effect. Finally, the study did not attempt to model all possible attributes associated with pharmacy benefit plans, such as the use of mail-service pharmacy or threetier copays.

These limitations do not affect the internal validity of the study's results. They do, however, limit the extent to which the results can be generalized.

\section{Implications}

When designing plans, pharmaceutical benefit managers need to balance the issues of drug availability, provider access, and cost. The use of conjoint analysis can help identify plan features that consumers prefer and the extent of those preferences. The consumers in this study indicate that the freedom to choose drugs was more important than out-of-pocket cost or pharmacy access. However, preference for this attribute was influenced by other elements of the plan.

Plan designers can use information from CA to decide whether potential savings in plan design can be balanced with the impact on consumer preferences for the plan. For example, restricting pharmacist access for this sample will have the least impact on consumer preferences but also will have the least potential for savings-pharmacy compensation is already very low. The greatest potential for cost savings in pharmacy plans lies in controlling drug costs through mechanisms such as the use of a formularythe attribute with the greatest impact on consumer preferences.

Drug benefit designers can use CA results to model the tradeoff between preferences and cost savings. Benefit managers can combine forecasts of estimated savings for plan changes (e.g., a restricted pharmacy network) with the results of consumer preferences for those changes in order to identify which plan design will produce the greatest savings with the least impact on preferences. This can provide benefit plans with an additional method 
for predicting the impact of changes in drug benefit design on consumer satisfaction.

It is also interesting to contrast the findings of this study with research on preferences for health plans. The attribute patients most preferred in choosing health plans is access to the physician. ${ }^{3}$ For this study of prescription drug benefit plans, the most preferred attribute is the freedom to have the drug chosen for you by your physician. Therefore, it appears that the determinant attribute in choosing medical and pharmacy benefit plans may both be an extension of the physician's expertise and decision for the patient.

\section{Future Research}

It would be valuable to conduct a more detailed benefit plan assessment with a more geographically diverse population and using a different group of attributes and attribute levels. It would also be useful to assess how pharmacy benefits are chosen in relation to other medical plan criteria.

\section{Conclusion}

Health plans use a number of different methods of cost containment to control the costs of prescription drugs. Typically, these include restrictions on which products will be reimbursed, which pharmacies consumers may patronize, or the imposition of higher copays. Implementing any type of restriction will result in some degree of consumer dissatisfaction. The results of this exploratory survey indicate that health plans can expect the most dissatisfaction to result from restrictions on product choice, especially when the restrictions involve therapeutic (as opposed to generic) interchange. Health plans can expect somewhat less dissatisfaction from increasing consumer cost-sharing and less still from restricting access to pharmacies. These results indicate the potential usefulness of considering consumer preferences and trade-offs in the design of drug benefit plans.

\section{DISCLOSURES}

This research was funded by the National Community Pharmacists Association, formerly the National Association of Retail Druggists. Author David Holford discloses that he received funding for unrelated research in pharmacoeconomics from PhRMA. Author Norman $V$. Carroll discloses that he has received research funding from Pfizer for unrelated cost of illness research. Both authors assert that neither funding source exerted any influence on the results of this research. Holdford served as principal author on this paper. Study concept and design, analysis and interpretation of data, drafting of the manuscript, critical revision of the manuscript, and statistical expertise was conducted jointly and equally by the authors. Administrative, technical, and/or material support was provided by Virginia Commonwealth University School of Pharmacy.

\section{REFERENCES}

1. Levitt KR, Cowan CL, Lazenby HC, et al. Health spending in 1998: Signals of change. Health Affairs 2000;19:124-32.

2. Anders G. Polling quirks give HMOs healthy ratings. Wall Street Journal 1996 Aug 27.

3. Gates R, McDaniel C, Braunsberger K. Modeling consumer health plan choice behavior to improve customer value and health plan market share. Journal of Business Research 2000;48(3):247-57.

4. Balsbaugh TA, Chambers CV, Diamond JJ. Asthma controller medications: What do patients want? J Asthma 1999;36(7):591-96.

5. Singh J, Cuttler L, Shin M, Silvers JB, Neuhauser D. Medical decision-making and the patient - Understanding preference patterns for growth hormone therapy using conjoint analysis. Medical Care 1998;36(8):AS31-AS45.

6. Green P, Kreiger E, Abba M. Segmenting markets with conjoint analysis. Journal of Marketing 1991;55(October):20-31.

7. Watrous M. Assessing the value of pharmaceuticals using economic, clinical, humanistic outcomes and the influence of perspective (prescription). Ph.D. Dissertation. Columbia, S.C.:University of South Carolina, 1995.

8. Carroll NV, Gagnon JP. Identifying consumer segments in health service markets: An application of conjoint and cluster analysis to the ambulatory care pharmacy market. J Health Care Marketing 1983;3(3):22-34.

9. Carroll NV, Perri M, Eve E, Kotzan JA, Fincham JE. Estimating demand for health information: pharmacy counseling services. J Health Care Marketing 1987;7(4):33-40

10. Hansen J. Consumer acceptance of HMO pharmacy services: a conjoint analysis, Ph.D. Dissertation. Columbia, S.C.: University of South Carolina, 1988.

11. Johnson FR, Desvousges WH, Ruby MC, Stieb D, De Civita P. Eliciting stated health preferences: An application to willingness to pay for longevity. Medical Decision Making 1998;18(2):S57-S67

12. Johnson FR, Banzhaf MR, Desvousges WH. Willingness to pay for improved respiratory and cardiovascular health: A multiple-format, statedpreference approach. Health Economics 2000;9(4):295-317.

13. Markham FW, Diamond JJ, Hermansen CL. The use of conjoint analysis to study patient satisfaction. Evaluation \& the Health Professions 1999;22(3):371-78

14. Osman LM, McKenzie L, Cairns J, Douglas JG. Patient weights for asthma symptoms: An investigation of patient preferences using conjoint analysis. Am J Respiratory and Crit Care Med 1999;159(3):A692.

15. Ratcliffe J, Buxton M. Patients' preferences regarding the process and outcomes of life-saving technology-An application of conjoint analysis to liver transplantation. Intern J Tech Assess in Health Care 1999;15(2):340-51.

16. Ryan M, Hughes J. Using conjoint analysis to assess women's preferences for miscarriage management. Health Economics 1997;6(3):261-73.

17. Szeinbach SL, Barnes JH, McGhan WF, Murawski MM, Corey R. Using conjoint analysis to evaluate health state preferences. Drug Information Journal 1999;33(3):849-58.

18. Terayama Y, Yamamoto M, Honda M, Gotoh F. Measurement of quality of life in migraine:Application of conjoint analysis. Annals of Neurology 2000; 48(3): 24

19. Chakraborty G. Ettenson R, Gaeth G. How consumers choose health insurance. J Health Care Marketing 1994;14(1):21-33.

20. Gustafsson A, Hermann F, Huber F. Conjoint Analysis as an Instrument of Market Research Practice. In: Conjoint Measurement: Methods and Applications. New York, NY.: Springer, 2000.

21. The SAS System for Windows. Cary, NC.: SAS Institute, 1996

22. Acito F, Jain AK. Evaluation of conjoint analysis results: a comparison of methods. J Marketing Research 1980;17:106-12.

23. Aventis Pharmaceuticals. Managed Care Digest Series 2000: HMO-PPO / 
Medicare-Medicaid Digest. Bridgewater, N.J.: Aventis Pharmaceuticals: 2001. 24. Aventis Pharmaceuticals. Managed Care Digest Series 2000: Managed Care Trends Digest 2000. Bridgewater, N.J.: Aventis Pharmaceuticals: 2000.

25. Pharmacy Benefit Management Institute, Inc. The Wyeth-Ayerst Prescription Drug Benefit Cost \& Plan Design Survey Report: 2000 Edition. Scottsdale, AZ: Pharmacy Benefit Management Institute, Inc.: 2000.

26. Pharmacy Benefit Management Institute, Inc. The 1996 Prescription Drug Benefit Cost \& Plan Design Survey Report. Scottsdale, AZ: Pharmacy Benefit Management Institute, Inc.: 1997.
27. Quintiles. Scott-Levin launching managed care series with benefit design-How it's changing managed care. Available at http:/www.quintiles.com. Accessed August 1, 2001.

28. HIRC. Three-tier copays penetrate $40 \%$ of HMOs. Available at http:/www.hirco.com/index.cfm/Fuseaction/ViewNews/ID/5.htm. Accessed May 4, 2001.

29. Perlstein, S. Four-tier approach injects consumerism into drug benefit. Managed Care 2001;10(8):21-24. 